\title{
Editorial
}

\section{Business Models and Sustainable Development Goals}

\author{
Prescott C. Ensign (1)
}

\section{check for updates \\ Citation: Ensign, P.C. Business Models and Sustainable Development Goals. Sustainability 2022, 14, 2558. https://doi.org/ $10.3390 /$ su14052558}

Received: 11 February 2022 Accepted: 16 February 2022 Published: 23 February 2022

Publisher's Note: MDPI stays neutral with regard to jurisdictional claims in published maps and institutional affiliations.

Copyright: (C) 2022 by the author. Licensee MDPI, Basel, Switzerland. This article is an open access article distributed under the terms and conditions of the Creative Commons Attribution (CC BY) license (https:// creativecommons.org/licenses/by/ $4.0 /)$.
Lazaridis School of Business \& Economics, Wilfrid Laurier University, Waterloo, ON N2L 3C7, Canada; ensign@wlu.ca

In 2015, all 193 member countries of the United Nations adopted the 2030 Agenda for Sustainable Development. It includes 17 Sustainable Development Goals (SDGs). Building on the principle of "leaving no one behind," it emphasizes a holistic approach to achieving sustainable development [1]. The 2020 environmental, social and governance (ESG) scoring and reporting document from the Organization for Economic Co-operation and Development (OECD) notes that sustainability investing has grown, primarily due to the number of funds and investors that have added ESG approaches to their overall agenda. Corporations, central banks and the public sector are placing a new emphasis on a greener environment and low-carbon economy [2]. The 2020s was to be a decade of action but progress has been slow, stalled or reversed in meeting the 17 SDG targets [3]. OECD's quantitative analysis provides an indication of the progress made and challenges still ahead with regard to sustainable development. The wide variety of metrics, methodologies, and approaches indicate a high number of disparate outcomes that are open to interpretation [4].

The outcome of the 26th UN Climate Change Conference (COP26) held in Glasgow Scotland (November 2021) is also open to interpretation. COP26 participants took steps to address the climate crisis by agreeing "to revisit and strengthen the 2030 targets in their nationally determined contributions ... by the end of 2022" [4]. These steps fall far short of delivering the national commitments necessary for a unified global effort to limit annual planet warming to $1.5^{\circ} \mathrm{C}[5,6]$. To find real SDG and ESG progress, we have to look past "agreements" by world leaders and metrics designed to influence institutional investors. We need to identify, explore and examine SDGs at multiple organizational levels-firm, sector, regional and national levels. This is where change, success and hope for our planet's future rests.

This Special Issue on "Business Models and Sustainable Development Goals" presents five research studies that examine transformative business models designed to support achievable sustainable development. Every organization-from start-ups, small and medium size enterprises, multinationals, social enterprises, hybrids, cooperatives, nonprofits to NGOs and government agencies-has a business model. It reflects management's explicit or implicit hypotheses on why and how the organization functions. The business model is the engine that powers an organization, defining the value proposition of the venture, how it balances resources with the ecosystem where it operates, how it generates cash flow and creates value [7]. Changes to an organization's business model are recognized as a fundamental approach to implementing innovations for sustainability. The capability to transform or transition to new business models is an important source of sustainable competitive advantage and provides leverage to improve the performance of organizations. Borrowing from Geissdoerfer and Vladimirova, a sustainable business model (SBM) includes pro-active management, monetary and non-monetary value for a broad range of stakeholders, and a long-term perspective [8].

The first study by Ramanauskaité, The Role of Incumbent Actors in Sustainability Transitions: A Case of LITHUANIA, explores actions at the organization, sector, regional and national level by five influence-shaping organizations that espouse a sustainability orientation. As a country, Lithuania has faced precipitous change since it obtained independence from the Soviet Union and is now an EU and NATO member. This has been a 
time of accelerated transition for companies moving from a planned economy to a free market socio-economic system. The paper examines the next question: what will the transition to sustainability be like? An extensive review of the relevant literature suggests that resistance by key incumbent actors will negatively affect sustainability at multiple levels. However, interviews and secondary data obtained in the study reveal the following. The five powerful and prominent companies that are making transitions to sustainability were basically promoters and sponsors but still face tension and resistance. Ramanauskaité provides insight into the need for researchers and practitioners to understand the internal and external issues involved in transitioning a business model compared to transforming a business model. The study also provides insight on understanding the impact of corporate leadership on sustainability-insight that goes beyond the firm and sector to one that focuses at the national level.

The second paper by Ensign, Roy and Brzustowski, Decisions by Key Office Building Stakeholders to Build or Retrofit Green in Toronto's Urban Core, moves the focus of sustainability and business model inquiry to the urban office building sector and regional metroplex level. It focuses on aligning new and existing construction decisions to achieve sustainable environmental goals, e.g., the reduction of greenhouse gas (GHG) emissions. Motivation for the study was based on the following. The federal and provincial governments in Canada had set GHG emissions mitigation targets for 2030 based on the Paris Climate Agreement and the Pan-Canadian Framework. Toronto's City Council declared a climate emergency on 2 October 2019, joining a global call to recognize the urgency of the climate crisis and adopting a stronger emissions reduction target for Toronto-net zero by 2050 or sooner. In December 2020, Ottawa announced plans to raise the federal carbon tax from CAD 30/tonne to 170 /tonne by 2030 . Would these actions impact the office building sector? The aim of this study was to determine whether key stakeholders (real estate developers, institutional investors and owner landlords) would choose a business model for or against sustainability. The authors introduce a six-stage real estate development process approach used by the sector as a lens for identifying and understanding the point at which the decision for conventional or green construction is made. In urban core real estate development, the metrics of each project are unique and the process often more political than economic. Two hypotheses were proposed: Hypothesis $\left(\mathrm{H}^{1}\right)$ LEED (Leadership in Energy and Environmental Design) certification has a significant positive factor in the asking rent (market value); and Hypothesis $\left(\mathrm{H}^{2}\right)$ financial drivers will be more influential than non-financial drivers in a key stakeholder's decision to pursue LEED certification. Pearson correlation and linear regression analysis of data on 16 LEED and 52 conventional buildings did not find LEED certification to be statistically significant in explaining the variance in the net asking rent (market value). Interviews conducted with senior executives engaged in Toronto's real estate development sector provided qualitative data to test $\mathrm{H}^{2}$. The expert informants did not view LEED certification as a primary deciding factor but as one of a combination of factors that impact a firm's financial bottom line. Transcripts of these interviews offered insight on positional differences between real estate developers, institutional investors and commercial office space renters on SDGs, ESG and GHG emissions. Even when LEED construction is selected, the values, goals and actions of the key stakeholders involved represent a diversity of business models.

The third paper by Geldres-Weiss, Gambetta, Massa and Geldres-Weiss, Materiality Matrix Use in Aligning and Determining a Firm's Sustainable Business Model Archetype and Triple Bottom Line Impact on Stakeholders, presents a tool that can be used to enhance or transform a company's traditional business model (TBM) to a sustainable business model (SBM). It introduces the materiality matrix (MM) as a way for a company to review its business model with a more comprehensive understanding of the value creation processes that maximize the total value, not just the financial value for stakeholders. By way of explanation, the total value for stakeholders is a multidimensional view of material issues in environmental, social and governance/economics (ESG) as well as corporate social responsibility (CSR) that collectively influence the value creation process. Data used to 
test the MM design include what are typically presented during GRI (Global Reporting Initiative) sustainability assessment preparation. Linking the MM to the business model provides the ability to gauge, measure and account for value creation from both an internal and external perspective. MM can create a triple bottom line impact through shaping strategic elements in the firm's business model. The study looked at transforming the company's existing TBM into a more sustainable one (inside-out approach) by enabling the identification of the most appropriate business model archetype to incorporate innovation into its SBM (outside-in approach). A case study is presented of the large globally prominent Chilean winery Viña Concha y Toro S.A. (VCT) to illustrate how MM can be used in transforming TBM into an SBM archetype. Based on GRI reports and interviews the authors chart and analyze the changes in VCT's material issues and associated prioritization between 2017 and 2019. The VCT case facilitates understanding how MM-aided changes impact an SBM archetype and value creation process. The case study also reports on the transformational alignment of the MM with implementation of a triple layered business model canvas (TLBMC) and SBM archetype. VCT's SBM holds that economic success goes hand in hand with caring for the environment, making rational use of natural resources and a commitment to people and the social sphere where VCT operates during each stage of the value chain.

The fourth paper by Mansell, Philbin and Broyd, Development of a New Business Model to Measure Organizational and Project-Level SDG Impact-Case Study of a Water Utility Company, introduces a methodological approach for linking local project-level sustainability performance to global SDG targets. Infrastructure construction project success has traditionally been measured (time, cost and scope/quality) when a project is completed (delivered). If engineers and project managers are the ones responsible for a construction project's sustainability, then performance measures agreed on by all the stakeholders need to begin at the project design phase. A recent Institution of Civil Engineers' survey of practitioners cites four critical factors for measuring a project's SDG success: clear definitions, holistic performance measurement tools, alignment of business priorities, and strong leadership. Having defined different ways of classifying project success, the authors suggest a new SDG transformation business model process for infrastructure projects and the infrastructure construction sector in general - the SDG infrastructure Impact-Value Chain (IVC). The conceptual basis embedded in the IVC is that there is a "golden thread" that links tactical SDG success during project construction and delivery to strategic SDG success that is embodied in longer-term post-project outcomes. Based on interviews and secondary sources, a case study of Anglian Water is presented to demonstrate the IVC new business model approach's use at the project design phase to align stakeholders on why/when/how/what SDG targets to measure. Anglian Water is one of the UK's largest water utility companies and a leading triple-bottom-line (TBL) sustainability supporter with a vision to create a resilient environment that allowed sustainable growth and the ability to cope with the pressures of climate change. Anglian Water's Wisbech project was then chosen as part of this case study because data on its delivery are open source on the Internet. This project is an IVC example because it was delivered by Anglian Water and its partners as part of their commitment to make a long-term impact on the market town of Wisbech (for more than the five years that the initial infrastructure project covered). Anglian Water wanted to assess whether a broad programme of social, economic and environmental changes in the lives of those in local communities can be linked to using the IVC. The SDG targets offer a framework to address the more diffuse outcomes and impacts that might not have been defined and measured using traditional project measurement approaches. The results of the case study investigation have indicated that there is a verifiable link across the IVC of activities-inputs-outputs during the "in-project" phase, connecting to the "post-project" outcomes and SDG impacts. The practical application of IVC is significant. With improved linkage of tactical delivery to strategic SDG impacts, improved investment decisions will be made and systemic-level lessons can be applied to increase the likelihood of success in achieving the SDG 2030 targets. 
The fifth paper by Doroteja, Marolt and Pucihar, Information Technology for Business Sustainability: A Literature Review with Automated Content Analysis, addresses the issue of managing sustainability in a digitalized environment. The authors conducted a systematic literature review and content analysis of 61 articles published between 2008 and 2020, providing insight on the role of information technologies (IT) in sustainable business models. They found that the majority of the research in this rapidly developing interdisciplinary field was from the European Union. This is not surprising since the 2018 European Commission states that competitiveness in the coming years will depend on sustainability and the ability to exploit IT. This strong interest in sustainability issues by EU policy makers and enterprises raises an important question. Could this be related to the two-tier system of corporate governance used in most EU enterprises? This dual system-a structure of management and a supervisory board with different roles-creates opportunities to focus on different values (e.g., environmental, social and governance criteria). Decisions in corporations with a unitary board system that consists of a single board of directors and absentee shareholders such as in the USA tend to focus on economic gains rather than social and environmental concerns. During the last decade, digital transformation has resulted from the emergence of new technologies (e.g., social, mobile, analytics, artificial intelligence, cloud, high-performance computing, Internet of Things, and robotics) that have an impact on individuals, enterprises, organizations and society. In a business context, digital transformation often refers to a process of redesign or innovation of a business model from the adoption and use of IT to create digital capabilities. This study suggests that the transformation of IT's role is bringing about sustainability. IT and digital capacities are not limited to reactive innovation and application. IT can play a major role as an enabler and driver for pro-active transformation of a traditional business model to a sustainable business model as well as create new value propositions.

The goal of this Special Issue was to provide a platform for scholars to share theorybased research, conceptualization, and case studies. These papers broaden and accelerate our understanding of innovative business models that support sustainable development. I trust that you the reader will find that this eclectic collection of papers presents an interesting examination of the internal and external challenges of aligning business models to achieve SDGs. A sincere thank you to all the Special Issue authors for their contribution to enhancing our understanding and providing valuable insights. A special thank you to the external peer reviewers for providing valuable feedback, comments and suggestions to improve the significance of the contributions. Finally, we want to express our thanks to the staff members at the MDPI editorial office, in particular Dana Shen, for their valuable support and encouragement.

Funding: Ensign received support from the Social Sciences and Humanities Research Council of Canada as well as a Principles for Responsible Management Education seed grant from the Lazaridis School of Business \& Economics.

Conflicts of Interest: The author declares no conflict of interest.

\section{References}

1. United Nations. The 17 Goals. Available online: https://sdgs.un.org/goals (accessed on 23 January 2022).

2. Boffo, R.; Patalano, R. ESG Investing: Practices, Progress and Challenges; OECD: Paris, France, 2020; Available online: https: // www.oecd.org/finance/ESG-Investing-Practices-Progress-Challenges.pdf (accessed on 23 January 2022).

3. Stockholm Environmental Institute. Let's Get the SDGs Back on Track. 2020. Available online: https://www.sei.org/perspectives / lets-get-the-sdgs-back-on-track/ (accessed on 23 January 2022).

4. The Law Society. Reflecting on COP26: What Were the Key Outcomes? 2021. Available online: https://www.lawsociety.org.uk/ topics / climate-change/reflecting-on-cop26-what-were-the-key-outcomes (accessed on 23 January 2022).

5. University of Edinburgh. Was COP26 a Success? Available online: https://www.ed.ac.uk/impact/opinion/was-cop26-a-success (accessed on 23 January 2022).

6. Bomberg, E. COP26: Are we Looking for Success in the Wrong Places? University of Edinburgh. Available online: https: //www.ed.ac.uk/impact/opinion/cop26-looking-for-success-in-all-the-wrong-places (accessed on 23 January 2022). 
7. Teece, D.J. Business models, business strategy and innovation. Long Range Plan. 2010, 43, 172-194. [CrossRef]

8. Geissdoerfer, M.; Vladimirova, D.; Evans, S. Sustainable business model innovation: A review. J. Clean. Prod. 2018, 198, 401-416. [CrossRef] 